(for second case), the authors also consider the possibility of psychosocial nanism in both cases.

1413

\section{EXPERIENCE OF CHILD PROTECTION UNIT AT CHILDREN HOSPITAL LAHORE}

\author{
T. Sultan 1 , A.W. Rathore ${ }^{2}$, A.J.A. Samdani ${ }^{3}$, \\ N. Zafar ${ }^{4}$ \\ ${ }^{1}$ Paediatric Neurology, ${ }^{2}$ Paediatric Medecine, \\ ${ }^{3}$ Paediatrics, ${ }^{4}$ Child Protection Unit, Institute of \\ Child Health, Lahore, Pakistan
}

Background: In Pakistan there is no mandatory reporting of Child Abuse cases and no system exists to manage a child victim of any kind of abuse. The law enforcing agencies are apathetic, and the Social Welfare Department is completely inactive.

Methods: In order to optimally manage cases of Child Abuse and Neglect, Child Rights and Abuse Committee of Pakistan Pediatric Association and Pahchaan initiated a series of trainings for doctors, nurses, and other health care professionals with support form Save the Children Sweden and established a Hospital Child Protection Committee at Children Hospital Lahore in 2004. International Society for Prevention of Child Abuse and Neglect (ISPCAN) supported this initiative through exchange training program with Child Protection Unit, Manila. Since last five years the Child Protection Committee has been detecting cases and providing medical, psychological, social and legal support to the victims of child abuse. The initiative has gained acceptance in the country and has already been replicated in 15 hospitals and Children Hospital Lahore as the first Child Protection Unit in South Asia.

Results: Over the last three years the project managed to detect and manage about 380 cases of Child Abuse. Of these more than 350 were provided psychological care while 244 were given Social support. Financial help was offered to 65 patients. The major challenge is in obtaining legal support for the patients.

Conclusion: This paper describes the achievements and challenges faced by the committee in its transition to Child Protection Unit.
114

\section{DOES POLY-DRUG COMPARED TO SINGLE DRUG ABUSE DURING PREGNANCY AFFECT NEONATAL MANAGEMENT?}

\author{
E. Fenny ${ }^{1,2}$, K. Quinn', C. Young ${ }^{3}$, S. Gupta ${ }^{1,4}$ \\ ${ }^{1}$ Neonatal Paediatrics, University Hospital of \\ North Tees, Stockton on Tees, ${ }^{2}$ Medical School, \\ University of Newcastle upon Tyne, Newcastle \\ upon Tyne, ${ }^{3}$ University Hospital of Hartlepool, \\ Hartlepool, ${ }^{4}$ University of Newcastle upon Tyne, \\ Newcastle upon Tyne, UK
}

Background/aims: Substance misuse is on rise in UK, with limited data on outcomes of pregnancy. We planned to study outcomes in substance abusing pregnant mums including the effects of single vs. poly-drug abuse on newborn babies.

Methods: Data of all registered pregnancies in Stockton \& Hartlepool area was collected retrospectively for the period 1.1.2008 and 31.12.2009 using antenatal registry, delivery records and case notes. The data was analysed using SPSS 17.0.

Results: During the study period data on 7331 pregnancies was collected. Of these 77 were known 'substance abuser' during pregnancy and 7264 were 'healthy' pregnancies. Among 'substance abuser' complete data was available on 67 pregnancies. In this group, there were significantly higher rates of termination of pregnancy (TOP), miscarriages or still births (SB) as compared to healthy group (10\% vs. $0.78 \%, p<0.0001)$. Of these $23(38 \%)$ were 'Poly-drug' users. Among live born babies, $26(43 \%)$ required treatment for withdrawal \& 22(37\%) were discharged home on treatment. Poly-drug abuse as compared to single drug abuse did not affect the need for treatment $(43 \%$ vs. $43 \%$; $p=0.986)$, or those discharged home on treatment ( $38 \%$ vs. $35 \% ; p=0.811$ ). Poly-drug use however significantly increased the duration of stay on the neonatal unit (22 days vs. 9 days; $p<0.01$ ).

Conclusions: Poly-drug compared to single drug abuse significantly increases the duration of stay on the neonatal unit, but has no effect on the need for treatment or being discharged home on treatment. Among substance abusing women the rates of TOP, $\mathrm{SB}$ or miscarriage is significantly higher. 